\title{
Rapidly declining trend of signet ring cell cancer of the stomach may parallel the infection rate of Helicobacter pylori
}

\author{
Hiroshi Ohyama1,2,3, Dai Yoshimura', Yosuke Hirotsu², Kenji Amemiya², Hiroyuki Amano', Yuko Miura', \\ Hiroshi Ashizawa', Keiko Nakagomi', Shinya Takaoka', Kenji Hosoda', Yoji Suzuki', Toshio Oyama ${ }^{4}$, Masao Hada ${ }^{5}$, \\ Yuichiro Kojima ${ }^{1 *}$, Hitoshi Mochizuki ${ }^{1,2}$ and Masao Omata ${ }^{1,2,6}$
}

\begin{abstract}
Background: Studies indicate that gastric cancer (GC) incidence has decreased, whereas signet ring cell carcinoma (SRC) incidence has increased. However, recent trends in GC incidence are unclear. We used our hospital cancer registry to evaluate the changes in the incidence of GC, SRC, and non-SRC (NSRC) over time in comparison to changes in the $\mathrm{H}$. pylori infection rates over time.

Methods: We identified 2532 patients with GC enrolled in our registry between January 2007 and December 2018 and statistically analyzed SRC and NSRC incidence. The H. pylori infection rate in patients with SRC was determined by serum anti-H. pylori antibody testing, urea breath test, biopsy specimen culture, and immunohistochemical analysis $(\mathrm{HC})$ of gastric tissue. Additionally, genomic detection of $\mathrm{H}$. pylori was performed in SRCs by extracting DNA from formalin-fixed paraffin-embedded gastric tissue and targeting 165 ribosomal RNA of H. pylori.

Results: Overall, 211 patients had SRC (8.3\%). Compared with patients with NSRC, those with SRC were younger $(P<0.001)$ and more likely to be female $(P<0.001)$. Time series analysis using an autoregressive integrated moving average model revealed a significant decrease in SRC $(P<0.001)$ incidence; NSRC incidence showed no decline. There was no difference in H. pylori infection prevalence between the SRC and NSRC groups. IHC and genomic methods detected H. pylori in 30 of 37 (81.1\%) SRCs.
\end{abstract}

Conclusions: Reduction in $\mathrm{H}$. pylori infection prevalence may be associated with the decrease in the incidence of SRC, which was higher than that of NSRC.

Keywords: Signet ring cell carcinoma, Helicobacter pylori, Genomic detection, Epidemiology, Time series analysis

\section{Background}

Gastric cancer (GC) is the fifth most frequently diagnosed cancer and the third leading cause of cancer-related death worldwide [1]. Histologically, GC is classified into intestinal and diffuse types [2]. The intestinal type is related to corpus-dominant gastritis with intestinal metaplasia, whereas the diffuse type usually originates from superficial pangastritis without atrophy [3]. The intestinal type is often associated with Helicobacter pylori (H. pylori) infection,

\footnotetext{
* Correspondence: y-kojima@ych.pref.yamanashi.jp

${ }^{1}$ Department of Gastroenterology, Yamanashi Central Hospital, Yamanashi, Japan

Full list of author information is available at the end of the article
}

while the diffuse type is more often associated with genetic abnormalities [4].

Signet ring cell (SRC) carcinoma is a form of adenocarcinoma whose histologic diagnosis is based on microscopic characteristics defined by the World Health Organization (WHO) [1]. SRC is classified as diffuse type and non-SRC (NSRC) is mostly classified as intestinal type according to Lauren's classification [5]. SRC and NSRC are considered distinct biologic entities originating from different pathways of carcinogenesis [5, 6].

Epidemiologically, the worldwide decline in GC incidence has mainly been associated with a decrease in intestinal-type GC in western countries [7]. By contrast, the incidence of diffuse-type GC, particularly SRC, is

(c) The Author(s). 2019 Open Access This article is distributed under the terms of the Creative Commons Attribution 4.0 International License (http://creativecommons.org/licenses/by/4.0/), which permits unrestricted use, distribution, and reproduction in any medium, provided you give appropriate credit to the original author(s) and the source, provide a link to the Creative Commons license, and indicate if changes were made. The Creative Commons Public Domain Dedication waiver (http://creativecommons.org/publicdomain/zero/1.0/) applies to the data made available in this article, unless otherwise stated. 
reported to have increased $[7,8]$. SRC represented 28$70 \%$ of GC in western countries [8-10]. Moreover, SRC incidence has significantly increased by $6.5 \%$ per year on average, representing an approximately 10 -fold increase from 1973 to 2000 [8]. However, the trends in the incidence of SRC after 2000 have not been fully examined.

$\mathrm{GC}$ rates in Japan are one of the highest in the world, presumably because of the high $H$. pylori infection rate [11]. However, the prevalence of $H$. pylori infection has drastically decreased, i.e., from 80 to $90 \%$ in older generations born before around 1950 to $<10 \%$ currently in individuals aged $<20$ years [12]. According to a previous study using Joinpoint regression analysis, the prevalence of $H$. pylori infection in subjects born between 1927 and 1949 decreased from 48.6 to $43.5 \%$, with a decline of $0.2 \%$ per year. Subsequently, a rapid decline in the prevalence of $H$. pylori infection in those born between 1949 (43.5\%) and 1961 (22.7\%) was found, with a decline of $1.7 \%$ per year. Another decrease was observed between 1961 (22.7\%) and 1988 (6.3\%), with a decline of $0.6 \%$ per year. The drastic decline in the prevalence of H. pylori infection by birth year can be explained by the change in sanitary conditions during childhood, when $H$. pylori infection is predominantly acquired [13].

Treatment for $H$. pylori infection was developed in 2000; however, governmental health insurance plan coverage of this treatment was limited to patients with peptic ulcers. In February 2013, the indications for treatment were expanded to include chronic gastritis. Subsequently, it was estimated that the number of patients with successful $H$. pylori eradication drastically increased after 2013, doubling to $>1,300,000$ from approximately 650,000 per year between 2001 and 2012 [14].

In 2006, the Japanese government began to encourage hospitals to create cancer registries. In 2013 the government changed the law to mandate these registries, and enforcement began in 2016. Our hospital voluntarily initiated a cancer registry in 2006, and since then we have accumulated information on all malignant neoplasms seen at our hospital. From 2007 to 2018, our registry enrolled 22,674 patients with various cancer types. Using the registry data, we evaluated the changes in the incidence of GC, SRC, and NSRC over time in comparison to changes in $H$. pylori infection rates over time using time series analysis.

\section{Methods}

\section{Background}

Our hospital covers the central part of Kofu City (population 400,000) in the highland area of Mt. Fuji, which is $100 \mathrm{~km}$ west of Tokyo. Compared with the people in the metropolitan area of Tokyo, the people in our area tend to stay here for life, making it easier to obtain follow-up studies on the patients. Approval for this retrospective review study was obtained from the Institutional Review Board at Yamanashi Central Hospital. The requirement for written informed consent was waived by the institutional review board. Since clinical data and previously collected samples were used in this retrospective study, the use of an opt-out consent method was approved by the institutional review board.

\section{Pathological confirmation of SRC and NSRC}

Starting in January 2007, we registered all patients with histologically proven GC. By the end of 2018, 2532 patients had been enrolled, and all of them underwent surgery, endoscopic submucosal dissection, and/or biopsy for diagnosis and treatment. All SRC and NSRC cases were confirmed by pathological diagnosis. SRC was described according to the WHO classification, i.e., poorly cohesive tumor cells with prominent cytoplasmic mucin and a crescent-shaped eccentrically placed nucleus [15].

\section{Clinical features}

Age, sex, and clinical data (including dates of diagnosis, histopathological diagnosis, the Union for International Cancer Control TNM classification, types of treatment, and dates of death) of patients were all documented in the databases of the in-hospital cancer registry. With the help of the Japanese government and the recently established law, we obtained the mortality data of all $2532 \mathrm{pa}-$ tients. Background gastric mucosal atrophy was classified into four grades of severity (i.e., normal, mild, moderate, and marked) on the basis of the updated Sydney system by an expert pathologist (T. O.) using formalin-fixed and paraffin-embedded (FFPE) tissue [16].

\section{Detection of $H$. pylori infection Serological testing}

Blood samples of patients with GC were collected and used for serology testing; anti-H. pylori antibodies were detected by latex agglutination turbidimetry (BML, Tokyo, Japan). Patients with an anti-H. pylori antibody titer $>10$ $\mathrm{U} / \mathrm{mL}$ were classified as $H$. pylori antibody-positive.

\section{Urea breath test (UBT).}

The patients ingested 13C-labeled urea $(100 \mathrm{mg})$, which was converted to ${ }^{13} \mathrm{CO}_{2}$ by the urease enzyme produced by $H$. pylori if the bacteria were present in the stomach (BML). The released ${ }^{13} \mathrm{CO}_{2}$ diffused into the blood and was released from the lungs. The expired air was collected $20 \mathrm{~min}$ after ${ }^{13} \mathrm{C}$-labeled urea ingestion to measure the ${ }^{13} \mathrm{C} /{ }^{12} \mathrm{C}$ ratio. A positive result of the UBT was defined as a difference between baseline and test samples of $>2.5 \%$. 


\section{Bacterial culture}

Gastric mucosa specimens were collected from patients by endoscopic biopsy. The processed specimens were smeared in Helicobacter agar media (Nissui Pharmaceutical, Tokyo, Japan) and horse blood agar media (Kyokuto Pharmaceutical Industrial, Tokyo, Japan) and cultivated at $37^{\circ} \mathrm{C}$ in a microaerophilic environment.

\section{Immunohistochemical detection}

Immunohistochemical (IHC) detection was performed using 3- $\mu$ m-thick serial sections of FFPE tissue from resections or biopsies. The sections were deparaffinized, and antigen activation was performed by heat treatment in ethylenediaminetetraacetic acid solution at $\mathrm{pH}$ 8.0. Protein expression was evaluated on the 3 - $\mu$ m-thick FFPE sections with rabbit polyclonal anti-H. pylori antibodies (diluted 1:10; Institute of Immunology, Tokyo, Japan) using the Ventana BenchMark ULTRA (Roche, Tucson, Arizona) [17, 18].

\section{Genomic detection of $H$. pylori 165 ribosomal RNA (rRNA)}

For detection of $H$. pylori, we obtained FFPE tissues from patients with SRC. DNA was extracted from $10-\mu \mathrm{m}$-thick sections of FFPE using FormaPure DNA (Beckman Coulter, USA) with magnetic beads according to the manufacturer's instructions. DNA concentration was determined using the Nano Drop 2000 spectrophotometer (Thermo Fisher Scientific, Waltham, MA). Primers were designed to amplify the H. pylori $16 \mathrm{~S}$ rRNA region and generate $110 \mathrm{bp}$ polymerase chain reaction (PCR) products. Primer sequences were: forward (5'-.CTGGAGAGACTAAGCCCTCC-3'); reverse (5'-ATTACTGACGCTGATTGTGC-3') [19]. Each PCR was performed with $50 \mu \mathrm{L}$ of reaction solution containing $45 \mu \mathrm{L}$ of Platinum ${ }^{\mathrm{Tm}}$ PCR SuperMix High Fidelity (Thermo Fisher Scientific), $1 \mu \mathrm{L}$ each of forward and reverse primers, $1 \mu \mathrm{L}$ of nuclease-free water, and $2 \mu \mathrm{L}$ of extracted DNA. Reactions were subject to thermal cycling with the following conditions: $94{ }^{\circ} \mathrm{C}$ for $2 \mathrm{~min}, 45$ cycles of $94^{\circ} \mathrm{C}$ for $15 \mathrm{~s}, 60{ }^{\circ} \mathrm{C}$ for $15 \mathrm{~s}$, and $68^{\circ} \mathrm{C}$ for $30 \mathrm{~s}$. To determine the H. pylori-specific amplicon, $5 \mu \mathrm{L}$ of the PCR products was separated by electrophoresis on $2 \%$ agarose gel, stained with ethidium bromide and visualized on an FAS IV UV Illuminator (NIPPON Genetics, Japan) [20, 21]. Moreover, directsequencing was performed by the Sanger method using $16 \mathrm{~S}$ rRNA PCR products [22]. PCR products were purified using AMPure XP (Beckman Coulter) according to the manufacturer's instructions. Sanger sequencing was performed with BigDye Terminator v3.1 Cycle Sequencing Kit (Thermo Fisher Scientific) using forward or reverse primers. PCR products were purified BigDye XTerminator ${ }^{\text {тм }}$ Purification Kit and subsequently analyzed by 3500 Genetic Analyzer (Thermo Fisher Scientific). The nucleotide sequences were aligned by BLAST (https://blast.ncbi.nlm.nih. gov/Blast.cgi).

\section{Statistical analysis}

Student's $t$-test and the Mann-Whitney $U$ test were used to compare continuous variables, whereas the chisquared test and Fisher's exact test were used for comparison of categorical variables.

To evaluate time series data, namely, the incidence of SRC and NSRC, time series analysis was performed using the autoregressive integrated and moving average (ARIMA) model [23]. The ARIMA model-building process was designed to take advantage of associations in the sequentially lagged relationships that usually exist in data collected periodically. When stationarity was achieved using differencing, the ARIMA model was built, and the fitted ARIMA model was used to forecast the incidence.

A probability $(P)$ value of $<0.05$ was considered statistically significant. All statistical analyses were performed using SPSS software version 20.0 (IBM-SPSS, Inc., Chicago, IL, USA) and R software packages (version 3.3.3; R Development Core Team).

\section{Results}

\section{Clinical features of SRC and NSRC}

Histopathological analysis of the 2532 patients with GC prospectively registered from January 2007 to December 2018 revealed 211 cases of SRC (8.3\%) and 2321 of NSRC (91.7\%). The median age of patients with SRC was 64 years (range 29-94 years) and that of patients with NSRC was 73 years (range 27-99 years) (Table 1). Patients with SRC were significantly younger than those with NSRC $(P<0.001)$. A greater number of female patients were observed among patients with SRC $(P<0.001)$.

Peak ages associated with SRC and NSRC occurrence were the 60s and 70s, respectively (Fig. 1a). When SRC and NSRC were plotted on the basis of birth year, the

Table 1 Characteristics of SRC and NSRC patients

\begin{tabular}{llll}
\hline Variable & $\begin{array}{l}\text { SRC } \\
(n=211)\end{array}$ & $\begin{array}{l}\text { NSRC } \\
(n=2321)\end{array}$ & $P$ \\
\hline Age median, years (range) & $64(29-94)$ & $73(27-99)$ & $<0.001$ \\
Gender, n (\%) & & & $<0.001$ \\
Female & $110(52.1)$ & $666(28.7)$ & \\
Male & $101(47.9)$ & $1655(71.3)$ & \\
Clinical Stage, n (\%) & & & \\
IA & & & \\
IB & $107(50.7)$ & $1168(50.3)$ & \\
IIA & $33(15.6)$ & $186(8.0)$ & \\
IIB & $10(4.7)$ & $124(5.3)$ & \\
IIIA & $5(2.4)$ & $57(2.5)$ & \\
IIIB & $8(3.8)$ & $91(3.9)$ & \\
IIIC & $3(1.4)$ & $34(1.5)$ & \\
IV & $1(0.5)$ & $12(0.5)$ & \\
Unknown & $29(13.7)$ & $324(14.0)$ & \\
\hline
\end{tabular}

*Unknown cases were excluded from the statistical analysis NSRC, non-signet ring cell carcinoma; SRC, signet ring cell carcinoma 


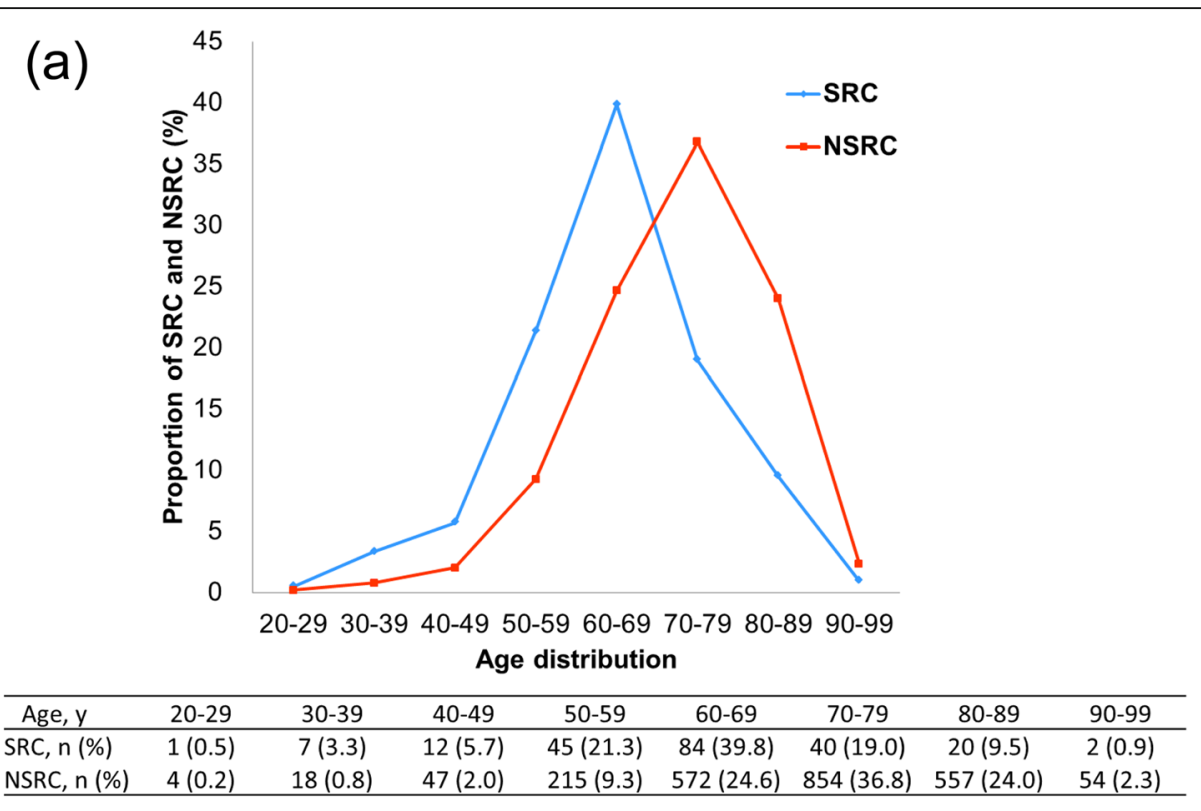

(b)

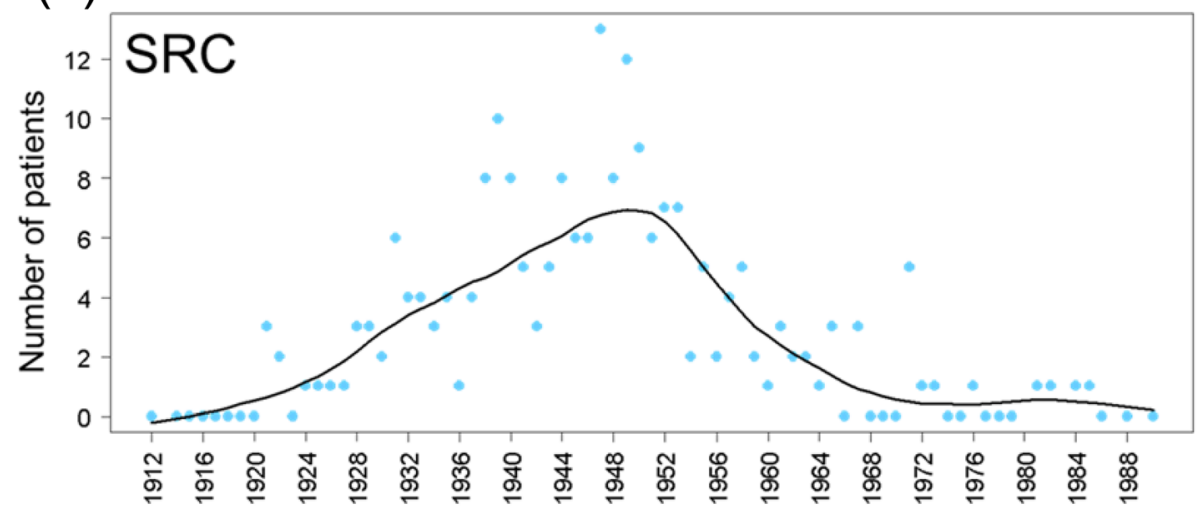

Birth-year

(c)

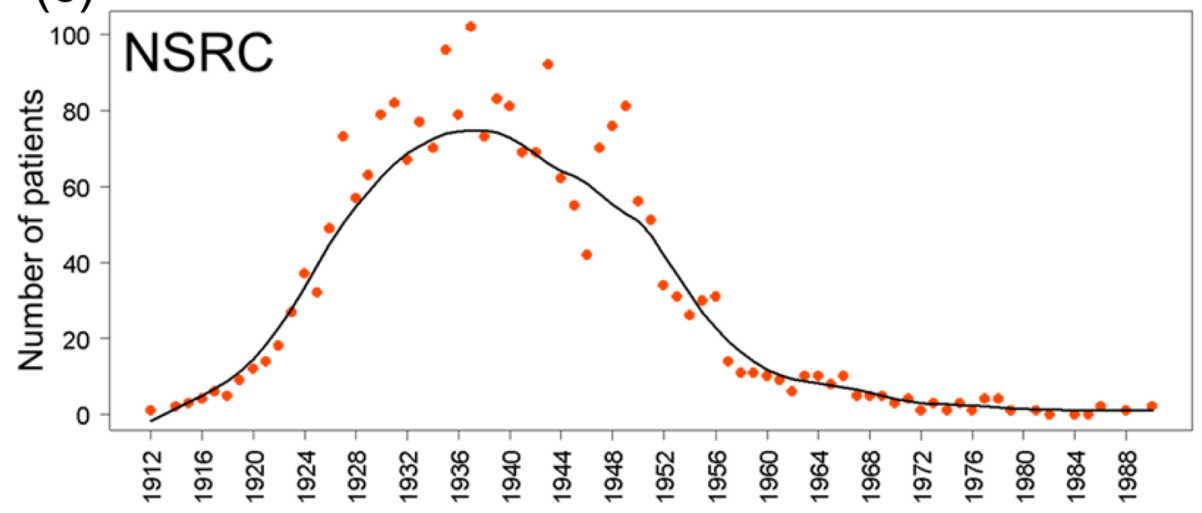

Birth-year

Fig. 1 (a) Age distribution of patients with SRC (blue line) and NSRC (red line). (b) Relationship between birth-year and the number of patients with SRC. (c) Relationship between birth-year and the number of patients with NSRC. Curved lines indicate approximate curves 
peak of SRC was between 1948 and 1952, whereas that of NSRC was between 1936 and 1940 (Fig. 1b and c).

\section{Annual incidence of SRC and NSRC}

Before 2012, the annual number of registered cases of SRC was 20-30, whereas after 2013, the number decreased to 9-17 (Fig. 2a). The annual numbers of registered cases of NSRC were 179 to 240 before 2012 and 176 to 206 after 2013. A comparison of the SRC/NSRC ratio in 2007-2012 with that in 2013-2018 showed that the latter was significantly lower $(141 / 1213(11.6 \%)$ vs. $70 / 1108$ (6.3\%), $P<0.001$ by the Mann-Whitney $U$ test) (Fig. 2a).

\section{Time fluctuation of the incidence of SRC and NSRC}

We used the ARIMA model to validate the declining trend of the incidence of SRC by modeling the number of SRC and NSRC using time series data from 2007 to 2018. The annual number of SRCs and the SRC/NSRC ratio significantly decreased $(P<0.001$ and $P=0.002$, respectively) (Fig. 2b-d). By contrast, the annual number of NSRCs did not change significantly.

\section{Clinical detection of $H$. pylori infection}

First, we retrospectively investigated the $H$. pylori infection rate using clinical records. Clinically employed methods included anti- $H$. pylori antibody testing, UBT, and bacterial culture. Of 211 SRC cases, only 25 (11.8\%) were tested by at least one of the three measures, whereas 729 of 2321 NSRC (31.4\%) cases were tested (Table 2). The difference was statistically significant $(P<0.001)$. Interestingly, although small in number, 15 of 25 SRC cases $(60.0 \%)$ and 387 of 729 NSRC cases (53.1\%) tested positive for $H$. pylori with at least one of the three testing methods (Tables 2 and 3). These data indicated that SRC had been regarded as being unrelated to $H$. pylori infection [24, 25]; thus, evaluation for $H$. pylori infection in patients with SRC is less frequent than that in patients with NSRC in the clinical setting. However, compared to that in NSRC, using the three aforementioned measures may yield similar or even higher $H$. pylori infection rates in SRC. Hence, IHC and genomic methods were additionally employed to detect $H$. pylori infection in SRC using archived FFPE gastric tissue in cases in which we could not obtain serum samples, breath, or fresh gastric tissue. We were able to retrieve 37 FFPE samples from 211 patients with SRC

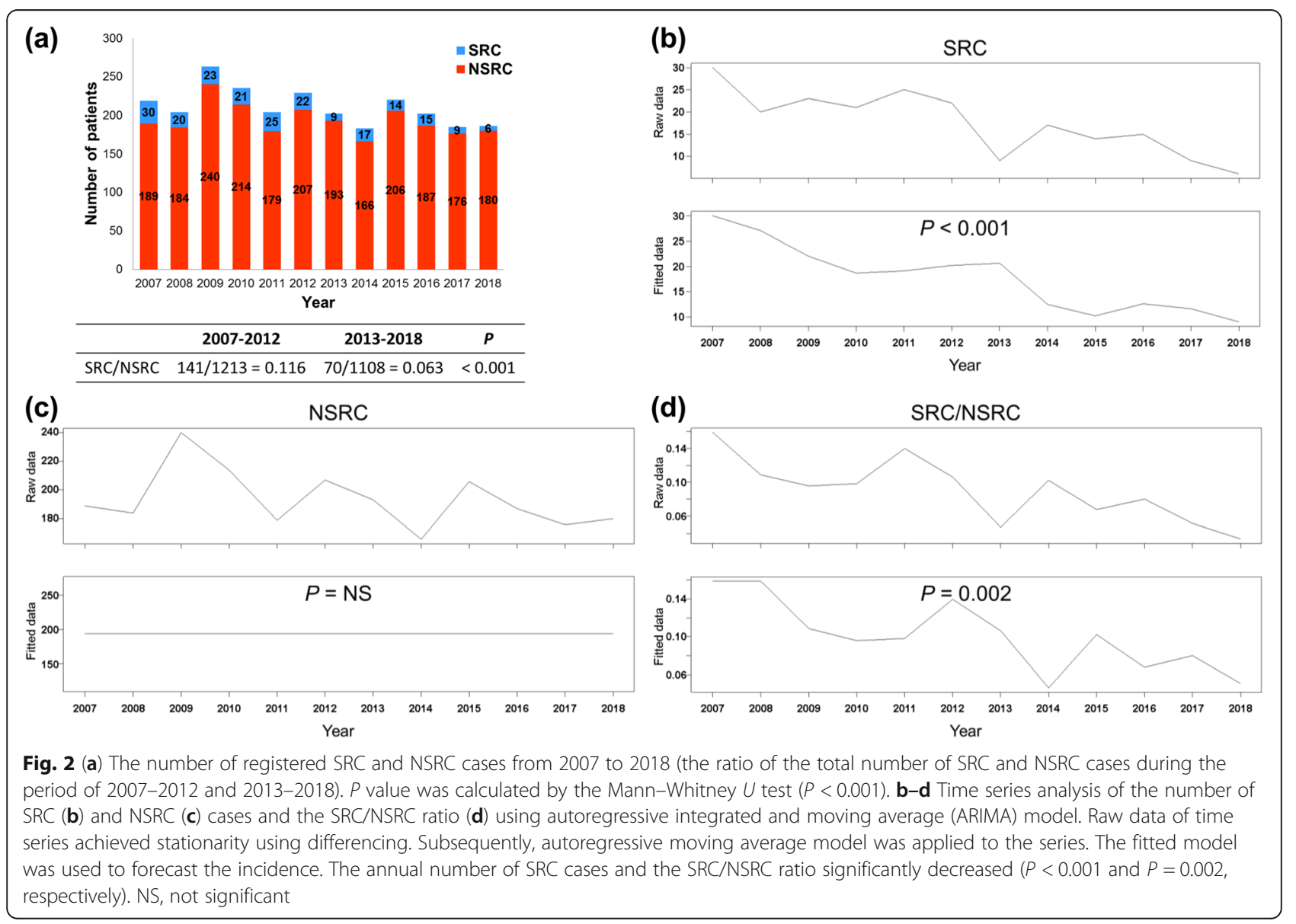


Table 2 The number of patients with SRC and NSRC who were tested for the presence of $H$. pylori infection

\begin{tabular}{lcll}
\hline & $\begin{array}{c}\text { Subjects in SRC } \\
(n=211)\end{array}$ & $\begin{array}{l}\text { Subjects in NSRC } \\
(n=2321)\end{array}$ & $P$ \\
\hline Testing for H. pylori infection, $\mathrm{n}(\%)$ & & \\
Ab & $6 / 211(2.8)$ & $117 / 2321(5.0)$ & 0.155 \\
UBT & $14 / 211(6.6)$ & $545 / 2321(23.5)$ & $<0.001$ \\
Bacterial culture & $11 / 211(5.2)$ & $486 / 2321(20.9)$ & $<0.001$ \\
At least one & $25 / 211(11.8)$ & $729 / 2321(31.4)$ & $<0.001$ \\
\hline Ab, anti-H. pylori antibody; NSRC, non-signet ring cell carcinoma; SRC, signet
\end{tabular}

$\mathrm{Ab}$, anti-H. pylori antibody; NSRC, non-signet ring cell carcinoma; SRC, signet ring cell carcinoma; UBT, urea breath test

(31 surgical specimens and 6 biopsies). Both genomic and IHC analyses of the 37 SRC cases revealed $22 \mathrm{H}$. pylori-positive cases (59.5\%) (Table 4). There were 26 cases $(70.3 \%)$ in which either genomic or IHC analysis was $H$. pylori-positive. Sanger sequencing using $16 \mathrm{~S}$ rRNA PCR products revealed that sequences of PCR products were matched to $H$. pylori genomic sequence (Additional file 1). Eventually, combining the clinical tests (antibody, UBT, and culture) and the two additional methods (IHC and genomic methods) showed that at least one approach tested positive for $H$. pylori infection in 30 of the 37 SRC cases (81.1\%) (Table 4).

\section{Background gastric mucosal atrophy in SRC and NSRC}

To investigate the background gastric mucosal atrophy in GC, we searched for histopathological findings on resected or biopsied specimens. We obtained 849 specimens, of which 807 were resected specimens (95.1\%). Of the 849 specimens, 123 belong to SRC cases and 726 to NSRC cases. Background gastric mucosal atrophy was noted in 109 SRC cases (88.6\%) and in 666 NSRC cases (91.7\%). No statistical difference in the incidence of background gastric mucosal atrophy between patients with SRC and NSRC was found $(P=0.257)$. However, glandular atrophy was less severe in patients with SRC than in patients with NSRC $(P<0.001$; Table 5$)$. Remarkably, marked atrophy was observed in only 5.7\% (7/ $123)$ of SRC and $20.5 \%(149 / 726)$ of NSRC $(P<0.001)$ patients. When the patients with SRC and NSRC were stratified according to glandular atrophy severity, patients with SRC were significantly younger than those

Table 3 Prevalence of $H$. pylori infection in patients with SRC and NSRC who were tested for the presence of $\mathrm{H}$. pylori infection

\begin{tabular}{lcll}
\hline & Positivity in SRC & Positivity in NSRC & $P$ \\
\hline Testing for H. pylori infection, $\mathrm{n}(\%)$ & & \\
$\mathrm{Ab}$ & $4 / 6(66.7)$ & $47 / 117(40.2)$ & 0.231 \\
UBT & $5 / 14(35.7)$ & $221 / 545(40.6)$ & 0.716 \\
Bacterial culture & $7 / 11(63.6)$ & $172 / 486(35.4)$ & 0.063 \\
At least one & $15 / 25(60.0)$ & $387 / 729(53.1)$ & 0.496 \\
\hline
\end{tabular}

$\mathrm{Ab}$, anti-H. pylori antibody; NSRC, non-signet ring cell carcinoma; SRC, signet ring cell carcinoma; UBT, urea breath test with NSRC, except for those in the marked atrophy group (Table 6).

\section{Discussion}

The morbidity and mortality of patients with GC have drastically decreased in the past 70 years [26]. Up to the 1980s, environmental factors, such as nutrition and socioeconomic conditions, were presumed to play a major role in the development of GC [27]. However, after the discovery of $H$. pylori in 1984 [28], the opinion on carcinogenesis of the stomach completely changed. In 1994, the International Agency for Research on Cancer classified $H$. pylori as a type I (definite) carcinogen in human beings [29]. Although GC is caused by multiple factors, H. pylori infection has been regarded as a main risk factor. $H$. pylori has been linked to chronic atrophic gastritis, which is an established precursor of the intestinal type of gastric carcinoma [30]. Thus, elimination of $H$. pylori has been considered the most important goal of $\mathrm{GC}$ reduction worldwide [30, 31].

In Japan, a dramatic decline in the prevalence of $H$. pylori infection, possibly attributable to improved hygiene, was observed in those born between 1949 and 1961 (43.5 and 22.7\%, respectively) [13]. In addition, the number of patients who have been cured of $H$. pylori infection by drug treatment is rapidly increasing in Japan. The nationwide estimated number of patients who were successfully treated was approximately 0.6 million per year between 2001 and 2012, which rapidly increased to around 1.4 million in 2013 [32].

SRC is a unique type of GC. Our data showed that 211 of 2532 GC cases (8.3\%) had SRC. The etiology and pathogenesis of SRC are completely unknown. SRC that is detected late is associated with an extremely poor outcome [7]. Clinically, we often treat relatively young female patients with diffuse-type GC (stage IV).

Several clinical studies have demonstrated the association of $H$. pylori infection with SRC. Asaka et al. reported that $86.4 \%$ of diffuse-type GC had a positive serology for $H$. pylori [33], and Kikuchi et al. reported that the frequency of positive $H$. pylori antibody in diffuse-type GC was $87.8 \%$ [34]. Huang et al. reviewed ten published studies and reported that $82.2 \%$ of patients with diffuse-type GC were seropositive for $H$. pylori [35]. On the contrary, there has been a long-held opinion that $\mathrm{SRC}$ is so unique that it is not related to $H$. pylori infection. Buruk et al. reported that $H$. pylori was found in $88 \%$ of the intestinal type and in only $55 \%$ of the diffuse type $(P<0.05)$ GCs $[1,24,25]$. Moreover, the implementation rate of clinical examination for $H$. pylori infection in SRC was low in this study, reflecting the prevalent opinion that diffuse-type GC or SRC is related to genetic or unknown factors rather than to obvious $H$. pylori infection (Table 2). However, with the addition of genomic 
Table 4 Prevalence of $H$. pylori infection in patients with SRC $(n=37)$

\begin{tabular}{|c|c|c|c|c|c|c|c|c|}
\hline No. & Age range* & Gender* & $\mathrm{IHC}$ & Genomic detection & $A b$ & UBT & Culture & At least one positive \\
\hline 1 & $50-59$ & 1 & + & + & NE & + & + & + \\
\hline 2 & $50-59$ & 2 & + & + & NE & + & NE & + \\
\hline 3 & $60-69$ & 1 & + & + & NE & + & NE & + \\
\hline 4 & $40-49$ & 2 & + & + & + & - & $N E$ & + \\
\hline 5 & $60-69$ & 1 & + & + & + & $\mathrm{NE}$ & NE & + \\
\hline 6 & $60-69$ & 2 & + & - & $\mathrm{NE}$ & NE & + & + \\
\hline 7 & $60-69$ & 1 & + & + & NE & $\mathrm{NE}$ & + & + \\
\hline 8 & $70-79$ & 1 & + & - & NE & NE & + & + \\
\hline 9 & $70-79$ & 2 & + & + & $\mathrm{NE}$ & - & $\mathrm{NE}$ & + \\
\hline 10 & $50-59$ & 2 & + & + & NE & $\mathrm{NE}$ & - & + \\
\hline 11 & $80-89$ & 2 & + & + & $\mathrm{NE}$ & $N E$ & - & + \\
\hline 12 & 30-39 & 1 & + & + & NE & $\mathrm{NE}$ & $\mathrm{NE}$ & + \\
\hline 13 & $40-49$ & 1 & + & + & NE & $N E$ & $N E$ & + \\
\hline 14 & $30-39$ & 2 & + & + & NE & $\mathrm{NE}$ & $\mathrm{NE}$ & + \\
\hline 15 & 40-49 & 1 & + & + & NE & $\mathrm{NE}$ & $\mathrm{NE}$ & + \\
\hline 16 & $40-49$ & 1 & + & + & NE & NE & $\mathrm{NE}$ & + \\
\hline 17 & $40-49$ & 2 & + & + & NE & $\mathrm{NE}$ & $\mathrm{NE}$ & + \\
\hline 18 & $30-39$ & 1 & + & + & $\mathrm{NE}$ & $\mathrm{NE}$ & $N E$ & + \\
\hline 19 & 30-39 & 1 & + & + & NE & $\mathrm{NE}$ & $\mathrm{NE}$ & + \\
\hline 20 & $40-49$ & 1 & + & + & NE & $\mathrm{NE}$ & $\mathrm{NE}$ & + \\
\hline 21 & $40-49$ & 2 & + & - & NE & $\mathrm{NE}$ & $\mathrm{NE}$ & + \\
\hline 22 & $30-39$ & 2 & + & - & $N E$ & NE & $\mathrm{NE}$ & + \\
\hline 23 & $60-69$ & 2 & - & + & - & - & $\mathrm{NE}$ & + \\
\hline 24 & $40-49$ & 2 & - & + & NE & - & $\mathrm{NE}$ & + \\
\hline 25 & $50-59$ & 2 & - & + & $\mathrm{NE}$ & - & $\mathrm{NE}$ & + \\
\hline 26 & $50-59$ & 2 & - & + & - & $\mathrm{NE}$ & $\mathrm{NE}$ & + \\
\hline 27 & 80-89 & 1 & - & - & + & - & - & + \\
\hline 28 & $60-69$ & 2 & - & - & NE & + & $N E$ & + \\
\hline 29 & $70-79$ & 2 & - & - & NE & + & $\mathrm{NE}$ & + \\
\hline 30 & $80-89$ & 1 & - & - & $\mathrm{NE}$ & $N E$ & + & + \\
\hline 31 & 70-79 & 2 & - & - & NE & - & $\mathrm{NE}$ & - \\
\hline 32 & $50-59$ & 1 & - & - & NE & $\mathrm{NE}$ & - & - \\
\hline 33 & $40-49$ & 2 & - & - & $N E$ & $\mathrm{NE}$ & $\mathrm{NE}$ & - \\
\hline 34 & $40-49$ & 1 & - & - & NE & $\mathrm{NE}$ & $N E$ & - \\
\hline 35 & 30-39 & 2 & - & - & $\mathrm{NE}$ & $\mathrm{NE}$ & $\mathrm{NE}$ & - \\
\hline 36 & $40-49$ & 1 & - & - & $\mathrm{NE}$ & $\mathrm{NE}$ & $\mathrm{NE}$ & - \\
\hline \multirow[t]{2}{*}{37} & $20-29$ & 1 & - & - & NE & $\mathrm{NE}$ & $\mathrm{NE}$ & - \\
\hline & & & $\begin{array}{l}22 / 37 \\
(59.5 \%)\end{array}$ & $\begin{array}{l}22 / 37 \\
(59.5 \%)\end{array}$ & $\begin{array}{l}3 / 5 \\
(60.0 \%)\end{array}$ & $\begin{array}{l}5 / 12 \\
(41.7 \%)\end{array}$ & $\begin{array}{l}5 / 9 \\
(55.6 \%)\end{array}$ & $\begin{array}{l}30 / 37 \\
(81.1 \%)\end{array}$ \\
\hline
\end{tabular}

*Age range was used instead of the exact age and genders were presented by 1 or 2 instead $\mathrm{F}$ or $\mathrm{M}$ for securing the patients' anonymity $\mathrm{Ab}$, anti-H. pylori antibody; IHC; immunohistochemical detection; NE, not examined; SRC, signet ring cell carcinoma; UBT, urea breath test

detection targeting $16 \mathrm{~S}$ rRNA of $H$. pylori and IHC detection of $H$. pylori utilizing FFPE, $H$. pylori infection was found in $81.1 \%$ of our registered SRC cases (Table 4).
GC is considered the end result of a long-lasting $H$. pylori infection leading to stomach epithelium atrophy with accumulated somatic mutations [36]. Thus, changes 
Table 5 Histopathological severity of background gastric mucosal atrophy in SRC and NSRC

\begin{tabular}{llll}
\hline & $\begin{array}{l}\text { SRC }(n=123) \\
\mathrm{n}(\%)\end{array}$ & $\begin{array}{l}\text { NSRC }(n=726) \\
\mathrm{n}(\%)\end{array}$ & $P$ \\
\hline Atrophy & & & \\
Normal & $14(11.4)$ & $60(8.3)$ & 0.257 \\
Mild & $62(50.4)$ & $253(34.8)$ & 0.001 \\
Moderate & $40(32.5)$ & $264(36.4)$ & 0.411 \\
Marked & $7(5.7)$ & $149(20.5)$ & $<0.001$ \\
\hline NSRC, non-signet ring cell carcinoma; SRC, signet ring cell carcinoma
\end{tabular}

in overall GC incidence due to eradication of the bacteria would be expected to occur extremely slowly. Nevertheless, an interesting finding was reported in an institution in Taiwan. A universal hepatitis B vaccination program in 1984 resulted in an immediate $50 \%$ decrease in the incidence of hepatocellular carcinoma in children within 13 years [37]. Previously it was thought that such a reduction in hepatocellular carcinoma incidence would take 30 to 40 years. The most common age range for the onset of hepatitis B-related hepatocellular carcinoma was 50 to 60 years, following development of chronic hepatitis and cirrhosis. Thus, the immediate effect was an unexpected result and led to postulating that hepatitis $B$ virus may directly induce hepatocellular carcinoma without preceding chronic hepatitis and cirrhosis.

Of further interest, marked atrophy was less common $(5.7 \%, 7 / 123)$ in patients with SRC than in those with NSRC $(20.5 \%, 149 / 726)$ (Table 5). These data indicated that despite the rate of $H$. pylori infection being the same as that of NSRC incidence the bacteria may not cause severe atrophy and may trigger SRC in the stomach in the short term instead (Table 6). Several clinical as well as basic studies on the pathogenesis of SRC have been conducted. Uemura et al. reported that diffuse-type GC is associated with active inflammation and not necessarily with marked atrophy [38]. Moreover, several important genetic abnormalities in GC have been reported. Approximately $1-3 \%$ of GC occurs because of an inherited gastric cancer predisposition [39]. Linkage analysis has implicated $C D H 1$ (also known as Ecadherin) mutations in approximately $25 \%$ of families with an autosomal-dominant predisposition to diffusetype GC [40]. The causal role of $H$. pylori infection for

Table 6 Age of patients with SRC and NSRC and the histopathological severity of gastric mucosal atrophy

\begin{tabular}{llll}
\hline & $\begin{array}{l}\text { SRC }(n=123) \\
\text { Age mean } \pm \text { SD }(n)\end{array}$ & $\begin{array}{l}\text { NSRC }(n=726) \\
\text { Age mean } \pm \text { SD }(n)\end{array}$ & $P$ \\
\hline Atrophy & & & \\
Normal & $56.6 \pm 13.4(14)$ & $66.0 \pm 12.1(60)$ & 0.012 \\
Mild & $63.5 \pm 11.5(62)$ & $67.7 \pm 11.4(253)$ & 0.011 \\
Moderate & $66.9 \pm 12.6(40)$ & $72.1 \pm 9.4(264)$ & 0.001 \\
$\quad$ Marked & $67.6 \pm 12.6(7)$ & $73.3 \pm 9.2(149)$ & 0.253 \\
\hline NSRC, non-signet ring cell carcinoma; SRC, signet ring cell carcinoma &
\end{tabular}

NSRC, non-signet ring cell carcinoma; SRC, signet ring cell carcinoma specific alterations in DNA methylation patterns was demonstrated in the gastric mucosa of $H$. pylori-infected patients and in $\mathrm{GC}$ cell lines [41]. Interestingly, $\mathrm{CDH1}$ gene methylation is reported in sporadic diffuse-type GC associated with $H$. pylori infection, and the methylation of the $C D H 1$ promoter could be reversed by the eradication of $H$. pylori [42]. Hence, H. pylori eradication therapy may decrease the incidence of diffuse-type GC by suppressing inflammation [43] and specific alterations of DNA methylation.

Our study has several limitations. First, we evaluated patients retrospectively; thus, we could not exclude various biases entirely. Second, this was a single-institutional study, so a small number of patients with SRC were evaluated. However, our data showed that the SRC incidence significantly decreased. Currently, although all available data indicate that the incidence of SRC continues to increase worldwide, no obvious explanation for the direct contribution of $H$. pylori infection to the development of SRC exists. However, studies on the increase in SRC incidence were published before 2005 [7, 8]. The government mandated national registry discussed earlier, by collecting cases from the entire nation of Japan, will enable epidemiological studies which may answer the question of whether SRC incidence is truly decreasing.

\section{Conclusions}

Reduction in SRC incidence seems more rapid than that in overall GC incidence on the basis of the findings of this study. The drastic decline in the prevalence of $H$. pylori infection by the improved hygiene may have contributed to the reduction in SRC. Moreover, eradication of $H$. pylori may hasten the decrease in the incidence of SRC.

\section{Supplementary information}

Supplementary information accompanies this paper at https://doi.org/10. 1186/s12876-019-1094-x

Additional file 1. Representative direct-sequencing result by the Sanger method using 165 rRNA PCR products. Sanger sequencing was performed to determine the nucleotide sequence of 165 rRNA PCR products and the sequences were validated by BLAST (https://blast.ncbi.nlm.nih. gov/Blast.cgi). As a result, sequences of PCR products were matched to $H$. pylori genomic sequence. (TIF $133 \mathrm{~kb}$ )

\section{Abbreviations}

ARIMA: the autoregressive integrated and moving average; FFPE: formalinfixed and paraffin-embedded; GC: gastric cancer; IHC: immunohistochemical; NSRC: non-signet ring cell carcinoma; PCR: polymerase chain reaction; rRNA: Ribosomal RNA; SRC: signet ring cell carcinoma; UBT: urea breath test; WHO: the World Health Organization

\section{Acknowledgments}

The authors would like to sincerely thank Ms. Ritsuko Yokouchi and Ms. Naho Sato for the collection of data on all malignant neoplasms at our hospital and for their assistance in drawing the figures. 


\section{Authors' contributions}

$\mathrm{HO}$, DY and MO planned research; HO, DY, HA1, YM, HA2, KN, ST, KH, YS, TO, $\mathrm{MH}, \mathrm{YK}, \mathrm{HM}$ and $\mathrm{MO}$ acquired the data; $\mathrm{HO}, \mathrm{DY}, \mathrm{YH}, \mathrm{KA}, \mathrm{HM}$ and $\mathrm{MO}$ analyzed and interpreted the data; $\mathrm{HO}$ and DY drafted the manuscript; $\mathrm{HO}$, $D Y, Y H$ and $M O$ made critical revisions related to important intellectual content of the manuscript; HO, DY, YK and MO made final approval of the version of the article to be published. All authors read and approved the final version of the manuscript.

\section{Funding}

This study was supported by the Japan Society for the Promotion of Science (JSPS) KAKENHI Early-Career Scientists (Grant Number JP18K16292 to YH), Research Grant for Young Scholars (to YH), the YASUDA Medical Foundation (to $\mathrm{YH}$ ), the Uehara Memorial Foundation (to $\mathrm{YH}$ ), and a Grant-in-Aid for Genome Research Project from Yamanashi Prefecture (to MO and $\mathrm{YH}$ ).

\section{Availability of data and materials}

All data supporting the conclusions of this article are included within the article. The datasets analyzed are available from the corresponding author on reasonable request.

\section{Ethics approval and consent to participate}

Approval for this retrospective review study was obtained from the Institutional Review Board at Yamanashi Central Hospital.

\section{Consent for publication}

The requirement for informed consent was waived by the institutional review board.

\section{Competing interests}

The authors declare that they have no competing interests.

\section{Author details}

'Department of Gastroenterology, Yamanashi Central Hospital, Yamanashi, Japan. ${ }^{2}$ Genome Analysis Center, Yamanashi Central Hospital, Yamanashi, Japan. ${ }^{3}$ Department of Gastroenterology, Graduate School of Medicine, Chiba University, Chiba, Japan. ${ }^{4}$ Department of Pathology, Yamanashi Central Hospital, Yamanashi, Japan. ${ }^{5}$ Department of Surgery, Yamanashi Central Hospital, Yamanashi, Japan. ${ }^{6}$ University of Tokyo, Tokyo, Japan.

\section{Received: 23 April 2019 Accepted: 16 October 2019}

\section{Published online: 08 November 2019}

\section{References}

1. Pernot S, Voron T, Perkins G, Lagorce-Pages C, Berger A, Taieb J. Signet-ring cell carcinoma of the stomach: impact on prognosis and specific therapeutic challenge. World J Gastroenterol. 2015;21:11428-38.

2. Correa P. Human gastric carcinogenesis: a multistep and multifactorial process- first American Cancer Society award lecture on Cancer epidemiology and prevention. Cancer Res. 1992;52:6735-40.

3. Conteduca V, Sansonno D, Lauletta G, Russi S, Ingravallo G, Dammacco F. H. pylori infection and gastric cancer: state of the art (review). Int J Oncol. 2013:42:5-18.

4. Hu B, El Hajj N, Sittler S, Lammert N, Bames R, Meloni-Ehrig A. Gastric cancer: classification, histology and application of molecular pathology. J Gastrointest Oncol. 2012;3:251-61.

5. Lauren P. The two histological main types of gastric carcinoma: diffuse and so-called intestinal-type carcinoma. An attempt at a histo-clinical classification. Acta Pathol Microbiol Scand. 1965;64:31-49.

6. Chon HJ, Hyung WJ, Kim C, Park S, Kim JH, Park CH, et al. Differential prognostic implications of gastric signet ring cell carcinoma: stage adjusted analysis from a single high-volume center in Asia. Ann Surg. 2017;265:946-53.

7. Piessen G, Messager M, Leteurtre E, Jean-Pierre T, Mariette C. Signet ring cell histology is an independent predictor of poor prognosis in gastric adenocarcinoma regardless of tumoral clinical presentation. Ann Surg. 2009; 250:878-87.

8. Henson DE, Dittus C, Younes M, Nguyen H, Albores-Saavedra J. Differential trends in the intestinal and diffuse types of gastric carcinoma in the United States, 1973-2000: increase in the signet ring cell type. Arch Pathol Lab Med. 2004;128:765-70.
9. Novotny AR, Schuhmacher C, Busch R, Kattan MW, Brennan MF, Siewert JR. Predicting individual survival after gastric cancer resection: validation of a US-derived nomogram at a single high-volume center in Europe. Ann Surg. 2006:243:74-81.

10. Cunningham SC, Kamangar F, Kim MP, Hammoud S, Haque R, Maitra A, et al. Survival after gastric adenocarcinoma resection: eighteen-year experience at a single institution. J Gastrointest Surg. 2005;9:718-25.

11. Hooi JKY, Lai WY, Ng WK, Suen MMY, Underwood FE, Tanyingoh D, et al. Global prevalence of Helicobacter pylori infection: systematic review and meta-analysis. Gastroenterology. 2017;153:420-9.

12. Inoue M. Changing epidemiology of Helicobacter pylori in Japan. Gastric Cancer. 2017;20:3-7.

13. Watanabe M, Ito H, Hosono S, Oze I, Ashida C, Tajima K, et al. Declining trends in prevalence of Helicobacter pylori infection by birth-year in a Japanese population. Cancer Sci. 2015;106:1738-43.

14. Hiroi S, Sugano K, Tanaka S, Kawakami K. Impact of health insurance coverage for Helicobacter pylori gastritis on the trends in eradication therapy in Japan: retrospective observational study and simulation study based on real-world data. BMJ Open. 2017;7:e015855.

15. Lauwers G, Carneiro F, Graham D, Curado M, Franceschi S. Gastric carcinoma. In: Bosman FT, Carneiro F, Hruban RH, Theise ND, editors. WHO classification of tumours of the digestive system. 4th ed. Lyon: IARC Press; 2010. p. 48.

16. Dixon MF, Genta RM, Yardley JH, Correa P. Classification and grading of gastritis. The updated Sydney system. International workshop on the histopathology of gastritis, Houston 1994. Am J Surg Pathol. 1996;20:1161-81.

17. Batts KP, Ketover S, Kakar S, Krasinskas AM, Mitchell KA, Wilcox R, et al. Appropriate use of special stains for identifying Helicobacter pylori: recommendations from the Rodger C. Haggitt gastrointestinal pathology society. Am J Surg Pathol. 2013;37:e12-22.

18. lijima Y, Hirotsu Y, Amemiya K, Ooka Y, Mochizuki H, Oyama T, et al. Very early response of circulating tumour-derived DNA in plasma predicts efficacy of nivolumab treatment in patients with non-small cell lung cancer Eur J Cancer. 2017;86:349-57.

19. Ho SA, Hoyle JA, Lewis FA, Secker AD, Cross D, Mapstone NP, et al. Direct polymerase chain reaction test for detection of Helicobacter pylori in humans and animals. J Clin Microbiol. 1991;29:2543-9.

20. Sakamoto I, Hirotsu Y, Nakagomi H, Ouchi H, Ikegami A, Teramoto K, et al. $B R C A 1$ and BRCA2 mutations in Japanese patients with ovarian, fallopian tube, and primary peritoneal cancer. Cancer. 2016;122:84-90.

21. Hirotsu Y, Kanda T, Matsumura H, Moriyama M, Yokosuka O, Omata M. HCV NS5A resistance-associated variants in a group of real-world Japanese patients chronically infected with HCV genotype $1 \mathrm{~b}$. Hepatol Int. 2015;9:424-30.

22. Hirotsu Y, Nakagomi H, Sakamoto I, Amemiya K, Oyama T, Mochizuki H, et al. Multigene panel analysis identified germline mutations of DNA repair genes in breast and ovarian cancer. Mol Genet Genomic Med. 2015;3:459-66.

23. Akhtar S, Rozi S. An autoregressive integrated moving average model for short-term prediction of hepatitis C virus seropositivity among male volunteer blood donors in Karachi. Pakistan World J Gastroenterol. 2009;15: 1607-12.

24. Buruk F, Berberoglu U, Pak I, Aksaz E, Celen O. Gastric cancer and Helicobacter pylori infection. Br J Surg. 1993;80:378-9.

25. Parsonnet J, Vandersteen D, Goates J, Sibley RK, Pritikin J, Chang Y. Helicobacter pylori infection in intestinal- and diffuse-type gastric adenocarcinomas. J Natl Cancer Inst. 1991;83:640-3.

26. Crew KD, Neugut Al. Epidemiology of gastric cancer. World J Gastroenterol. 2006:12:354-62.

27. Howson CP, Hiyama T, Wynder EL. The decline in gastric cancer: epidemiology of an unplanned triumph. Epidemiol Rev. 1986;8:1-27.

28. Warren JR, Marshall BJ. Unidentified curved bacilli on gastric epithelium in active chronic gastritis. Lancet. 1983;1:1273-5.

29. International Agency for Research on Cancer Working Group on the evaluation of carcinogenic risks to humans. Schistosomes, liver flukes, and Helicobacter pylori. IARC Working Group on the Evaluation of Carcinogenic Risks to Humans. Lyon, 7-14 June 1994. IARC Monogr Eval Carcinog Risks Hum. 1994; 61:1-241.

30. Parsonnet J, Friedman GD, Vandersteen DP, Chang Y, Vogelman JH, Orentreich $\mathrm{N}$, et al. Helicobacter pylori infection and the risk of gastric carcinoma. N Engl J Med. 1991;325:1127-31. 
31. Wu CY, Kuo KN, Wu MS, Chen YJ, Wang CB, Lin JT. Early Helicobacter pylori eradication decreases risk of gastric cancer in patients with peptic ulcer disease. Gastroenterology. 2009;137:1641-8.

32. Sugano K, Hiroi S, Yamaoka Y. Prevalence of Helicobacter pylori infection in Asia: remembrance of things past? Gastroenterology. 2018;154:257-8.

33. Asaka M, Kimura T, Kato M, Kudo M, Miki K, Ogoshi K, et al. Possible role of Helicobacter pylori infection in early gastric cancer development. Cancer. 1994;73:2691-4.

34. Kikuchi S, Wada O, Nakajima T, Nishi T, Kobayashi O, Konishi T, et al. Serum anti-Helicobacter pylori antibody and gastric carcinoma among young adults. Cancer. 1995;75:2789-93.

35. Huang JQ, Sridhar S, Chen Y, Hunt RH. Meta-analysis of the relationship between Helicobacter pylori seropositivity and gastric cancer. Gastroenterology. 1998;114:1169-79.

36. Cancer Genome Atlas Research Network. Comprehensive molecular characterization of gastric adenocarcinoma. Nature. 2014;513:202-9.

37. Chang MH, Chen CJ, Lai MS, Hsu HM, Wu TC, Kong MS, et al. Universal hepatitis $B$ vaccination in Taiwan and the incidence of hepatocellular carcinoma in children. Taiwan childhood Hepatoma study group. N Engl J Med. 1997;336:1855-9.

38. Uemura N, Okamoto S, Yamamoto S, Matsumura N, Yamaguchi S, Yamakido $\mathrm{M}$, et al. Helicobacter pylori infection and the development of gastric cancer. N Engl J Med. 2001;345:784-9.

39. Fitzgerald RC, Caldas C. Clinical implications of E-cadherin associated hereditary diffuse gastric cancer. Gut. 2004:53:775-8.

40. Guilford P, Hopkins J, Harraway J, McLeod M, McLeod N, Harawira P, et al. E-cadherin germline mutations in familial gastric cancer. Nature. 1998;392:402-5.

41. Nobili S, Bruno L, Landini I, Napoli C, Bechi P, Tonelli F, et al. Genomic and genetic alterations influence the progression of gastric cancer. World Gastroenterol. 2011;17:290-9.

42. Suerbaum S, Michetti P. Helicobacter pylori infection. N Engl J Med. 2002;347: 1175-86.

43. Shichijo S, Hirata Y, Niikura R, Hayakawa Y, Yamada A, Ushiku T, et al. Histologic intestinal metaplasia and endoscopic atrophy are predictors of gastric cancer development after Helicobacter pylori eradication. Gastrointest Endosc. 2016;84:618-24.

\section{Publisher's Note}

Springer Nature remains neutral with regard to jurisdictional claims in published maps and institutional affiliations.

Ready to submit your research? Choose BMC and benefit from:

- fast, convenient online submission

- thorough peer review by experienced researchers in your field

- rapid publication on acceptance

- support for research data, including large and complex data types

- gold Open Access which fosters wider collaboration and increased citations

- maximum visibility for your research: over $100 \mathrm{M}$ website views per year

At $\mathrm{BMC}$, research is always in progress.

Learn more biomedcentral.com/submissions 